\section{Esophageal Polyp as the Sole Manifestation of Relapse Seven Years After Treatment for Hodgkin's Disease}

In 1985, an 18-year-old man was admitted to our hospital for swelling of the cervical lymph nodes, without other symptoms. The histological diagnosis was: Hodgkin's disease, nodular sclerosis subtype. After therapy (polychemotherapy and radiation) he was symptom-free until 1992, when he started to complain of dysphagia. An esophagoscopy demonstrated a $4-\mathrm{cm}$ polypoid mass with a short, thick peduncle in the distal esophagus, partially extending into the gastric fundus (Figure 1). Two polypectomies were attempted using a snare. The biopsies obtained during both endoscopies were negative for malignancy. A third attempt at removal was performed with a combined technique: the polyp was reduced by laser, and the residual mass was removed with a snare. The pathologic diagnosis was relapse of Hodgkin's disease (Figure 2). Clinical, radiological, and laboratory examinations excluded the presence of Hodgkin's disease anywhere else.

Our case confirms some information on the anatomic and clinical features of Hodgkin's disease involvement of the esophagus:

1. Dysphagia must be considered a symptom possibly correlated to Hodgkin's disease in all its manifestations. Both in the present case and in those reported in the literature $(1,2)$, dysphagia was the leading symptom of relapse. Dysphagia was also the initial symptom in two patients with unsuspected Hodgkin's disease of the mediastinal nodes involving the esophagus $(3,4)$ and in a case of primary esophageal Hodgkin's disease (5).

2. Esophageal involvement may be the sole manifestation of relapse in patients affected by Hodgkin's disease. Two other cases of isolated esophageal relapse involving the distal third and the contiguous gastric fundus were reported nine (1) and ten years (2) after diagnosis of Hodgkin's disease.

3. Thorough evaluation should be carried out to exclude active disease in patients affected by Hodgkin's disease who complain of esophageal symptoms. In our case, relapse was not suspected, and repeated biopsies did not demonstrate the true nature of the esophageal polyp because of necrosis and inflammation at the site of biopsy. Failure to obtain diagnostic material through an endoscopic biopsy, as is frequently the case with submucosal tumors, has been previously reported (5).

\section{Acknowledgment}

This study was financed by the University of Trieste (Fund "60\%").

\section{Melato', S. Bucconi ', R. Fanin ${ }^{2}$, M. Baccarani ${ }^{2}$, L. Buri ${ }^{3}$}

${ }^{1}$ Institute of Anatomic Pathology, University of Trieste, Trieste, Italy; ${ }^{2}$ Department of Hematology, University of Udine, Udine, Italy; ${ }^{3}$ Department of Gastroenterology, U.S.L. No. 1 - Triestina, Trieste, Italy

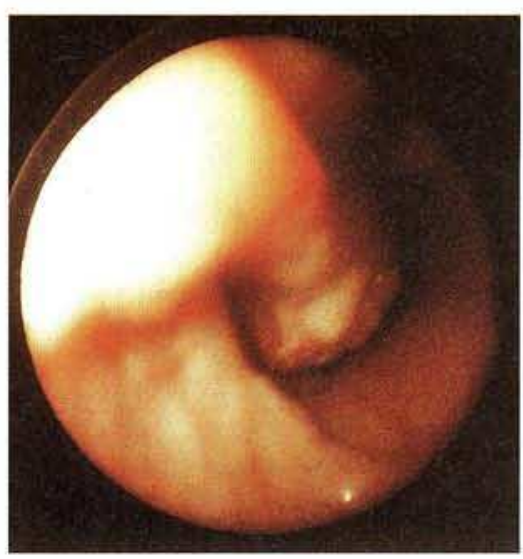

Figure 1:

Endoscopic appearance of the polyp in the lower third of the esophagus.

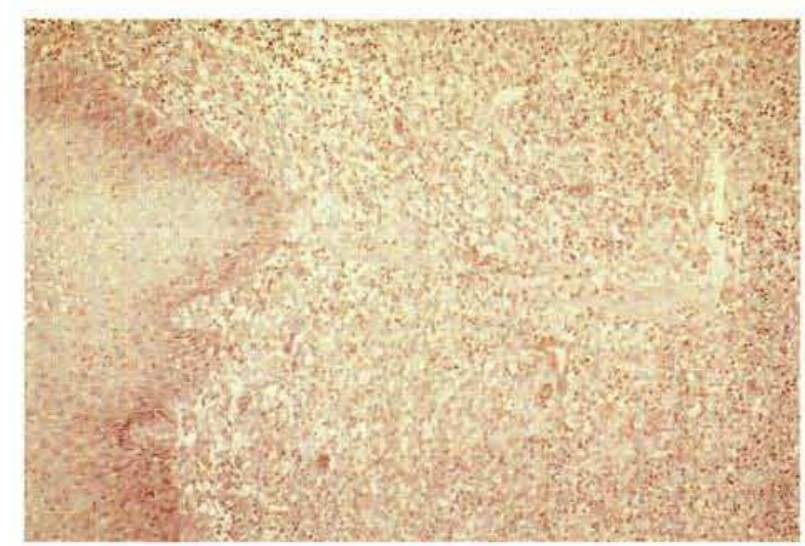

Figure 2: Massive neoplastic infiltration of the esophageal submucosa (hematoxylin and eosin, 20x).

\section{References}

1. Agha FP, Schnitzer B: Esophageal involvement in lymphoma. Am J Gastroenterol 1985; 80: 412-416.

2. Wodzinski MA, Gavalas M, Brown MJ, Thorpe JAC:Hodgkin's disease of the oesophagus. Acta Haematol 1988; 79: $221-223$.

3. Trotman BW, Glick JH, deBarros SGS, Atkinson BF: Dysphagia in a patient with Hodgkin's disease. J Am Med Assoc 1980; 244: $2552-2553$.

4. Hauteville $D$, Abgrall $J$, Chatelain $J D$ et al.: Localisation oesophagienne révélatrice d'une maladie de Hodgkin. Ann Méd Interne (Paris) 1987; 138: 38-40.

5. Stein HA, Murray D, Warner HA: Primary Hodgkin's disease of the esophagus. Dig Dis Sci 1981; 26: 457-461.

Corresponding Author

M. Melato, M.D., Istituto di Anatomia Patologica

Ospedale Maggiore, 34100 Trieste TS, Italy 